\title{
Impact of allopurinol on metabolic acidosis in patients with chronic kidney disease; a randomized controlled- trial
}

\author{
Davood Gholami ${ }^{1}$, Maryam Hami ${ }^{\mathbb{D}}$, Boshra Hasanzamani $^{2} \mathbb{D}$, Maryam Miri $^{*}(\mathbb{D}$ \\ ${ }^{1}$ Mashhad University of Medical Sciences, Mashhad, Iran \\ ${ }^{2}$ Kidney Transplantation Complications Research Centre, Mashhad University of Medical Sciences, Mashhad, Iran
}

\section{A R T I C L E I N F O}

Article Type:

Original

Article History:

Received: 7 Febraury 2019

Accepted: 23 April 2019

Published online: 5 May 2019

Keywords:

Chronic kidney disease

Allopurinol

Uric acid

Metabolic acidosis

Cardiovascular disease

\begin{abstract}
A B S T RA C T
Introduction: Chronic kidney disease (CKD) is a disabling disease with multiple complications, like, increased serum levels of uric acid due to glomerular filtration rate (GFR) impairment.

Objectives: This study was designed to evaluate the effect of allopurinol on metabolic acidosis in patients with renal failure.

Patients and Methods: This is a randomized controlled-trial study on 50 patients with CKD stage II-IV, who referred to Qaem and Montaserieh hospitals in Mashhad. Patients were selected and randomly divided into two equal groups of 25 subjects. In addition to standard treatments, the intervention group received $100 \mathrm{mg}$ allopurinol tablet for three months and the control group received placebo. Demographic data were obtained from each individual. Serum uric acid level, creatinine, blood $\mathrm{pH}$ and bicarbonate levels were assessed at the initiation of treatment and at the end of the third month.

Results: The mean age of patients was $54.04 \pm 12.62$ years. Allopurinol administration resulted in a significant increase of serum bicarbonate levels and $\mathrm{pH}(P<0.001$ for each) compared to the control group. A significant reduction in uric acid $(P<0.05)$ and an increase in GFR $(P<0.05)$ was observed in both groups.

Conclusion: Allopurinol could ameliorate metabolic acidosis, glomerular filtration and uric acid in patients with CKD.

Trial registration: This study was registered in Iranian Registry of Clinical Trial (identifier: IRCT2016122731604N1; https://irct.ir/trial/24831; registration date: 2017-08-05).
\end{abstract}

\section{Implication for health policy/practice/research/medical education:}

In a randomized controlled-trial study on 50 patients with chronic kidney disease stage II-IV, we found, allopurinol could ameliorate metabolic acidosis and glomerular filtration by reducing serum uric acid levels.

Please cite this paper as: Gholami D, Hami H, Hasanzamani B, Miri M. Impact of allopurinol on metabolic acidosis in patients with chronic kidney disease; a randomized controlled-trial. J Renal Inj Prev. 2019; 8(3): 216-220. DOI: 10.15171/jrip.2019.40.

\section{Introduction}

Chronic kidney disease $(\mathrm{CKD})$ is defined as chronic irreversible nephron damage either reduction in the number of nephrons or their function $(1,2)$. CKD presents with reducing the renal function with or without azotaemia or kidney damage for more than three months $(1,2)$. CKD is a global health issue which imposes high costs on nations (1). The prevalence of CKD was reported to be $13.4 \%$ for all five stages and $10.6 \%$ for stage II to $\mathrm{V}$ (1). CKD is associated with increased mortality mainly due to cardiovascular disease (CVD) and less importantly due to cancer (2).
Increased serum uric acid levels are commonly seen in CKD patients (3). For decades, increased serum uric acid was considered as a risk factor for CVD but recent epidemiological studies have shown that increased serum uric acid is associated with increased risk of hypertension, CKD, CVD and mortality $(3,4)$. Hyperuricemia has been shown to be related to hypertension, proteinuria, renal function impairment and progressive nephropathy as well as CVD. Animal studies have shown that the mechanism of injury by hyperuricemia is through endothelial cell damage, activation of renin-angiotensin-aldosterone system and increased oxidative stress $(5,6)$. Allopurinol is 
a xanthine oxidase inhibitor that inhibits the production of hypoxanthine from xanthine, a precursor of uric acid (7). Few studies assessing the effects of allopurinol on renal function and metabolic acidosis have shown that allopurinol prevents the progression of renal failure, its complications $(3,8)$ and metabolic acidosis (9).

\section{Objectives}

The aim of this study was to evaluate the effect of allopurinol administration on metabolic acidosis in CKD patients in Mashhad, Iran.

\section{Patients and Methods}

\section{Study design}

This randomized controlled trial was conducted on patients with CKD who referred to Qaem and Montaserieh hospitals, Mashhad, Iran. Subjects were selected based on convenient sampling (Patients randomly selected with double blinded method). Patients were included in the study if they were within the age range of 18 to 80 years, with the diagnosis CKD (stage II to IV), hyperuricemia (serum uric acid between 6 and $10 \mathrm{mg} / \mathrm{dL}$ ) and metabolic acidosis (serum bicarbonate between 15 and $20 \mathrm{mg} /$ dL). Subjects were excluded if they had positive history of gout disease, myeloproliferative disease, or previous consumption of allopurinol or allergy to allopurinol. Patients were randomly allocated to either intervention group who received $100 \mathrm{mg} /$ daily allopurinol or control group who received vitamin B1 as placebo in addition to conventional medications. The duration of intervention was three months. The Consort flow diagram of the study is presented in Figure 1.

The demographic information were obtained from all patients at baseline. Measurements included serum uric acid level, bicarbonate level, creatinine and $\mathrm{pH}$. Measurements were performed at baseline and at the end of the third month. Glomerular filtration rate (GFR) was calculated by CKD-EPI (chronic kidney disease epidemiology collaboration) equation formula.

\section{Ethical issues}

Human rights were respected in accordance with the Helsinki Declaration 1975, as revised in 1983. The study protocol was approved by the Ethical Committee of the Mashhad University of Medical Sciences (24/04/2016, Code: IR.MUMS.REC.1395.247). The purpose and procedure of the study was explained for patients. The informed consent was taken from the patients. This paper was extracted from the M.D thesis of Davod Gholami (\# 950015) in The Mashhad University of Medical Sciences. This study was also registered in Iranian registry of clinical trial (\#IRCT2016122731604N1; https://irct.ir/trial/24831; registration date: 2017-08-05). Mashhad University of Medical Sciences supported this study (Grant \#950015).

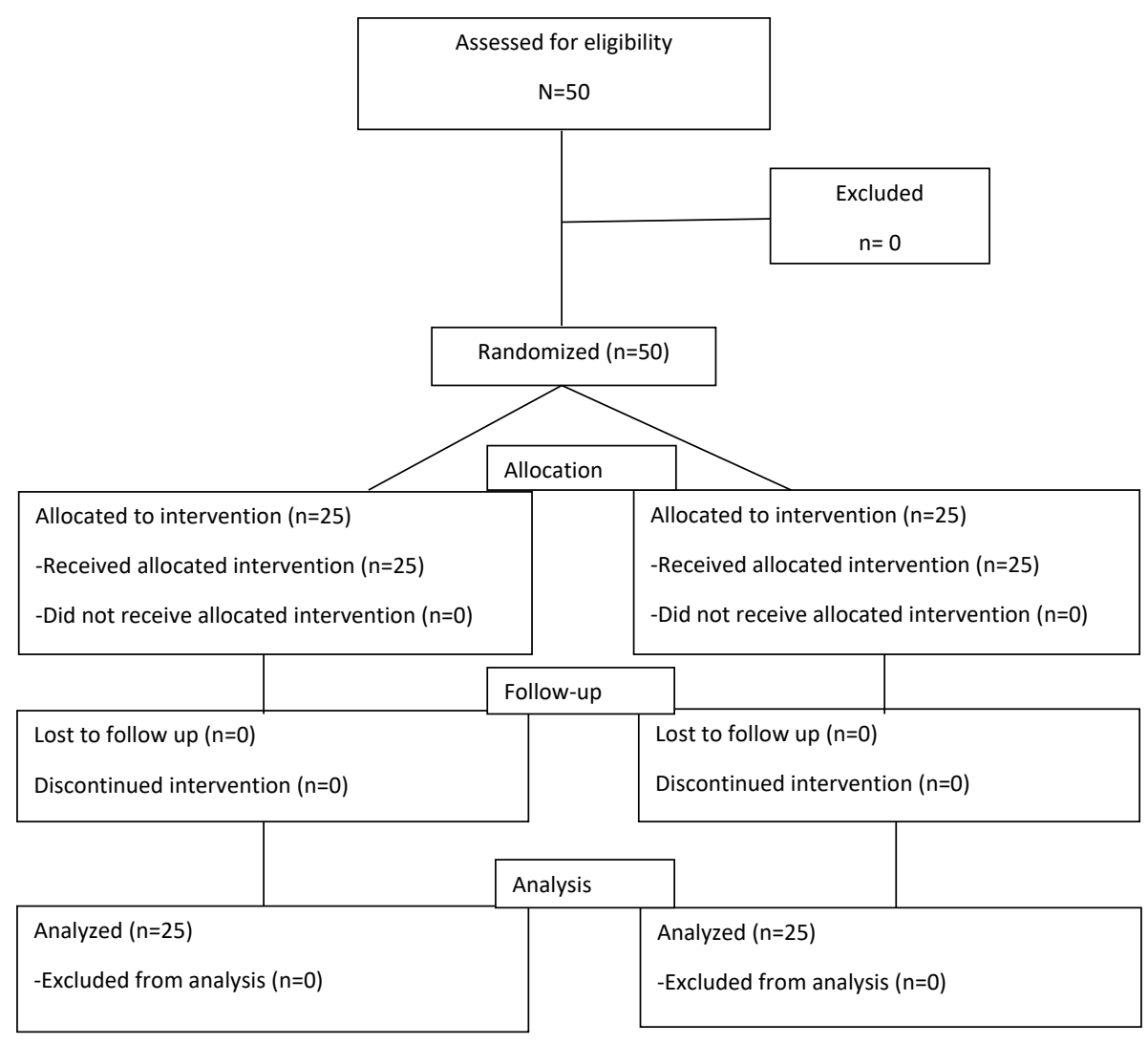

Figure 1. Consort flow diagram of the study 


\section{Statistical analysis}

Data were analyzed by the statistical package for social sciences (SPSS) version 22 (IBM Inc. Chicago, Il, USA). Continuous variables were checked for normality using the Shapiro-Wilk test and were presented as mean and standard deviation (SD). Categorical variables were presented as frequency and percentage. Comparison of continuous demographic variables between groups was performed by independent student $t$ test while the chisquared test was used to compare the distribution pattern of categorical variables. The repeated measures analysis of covariance (ANCOVA), with diastolic blood pressure as covariate, was used to assess the group, time and timex group effects of intervention and to compare changes in study variables between and within the groups.

Results

Totally 50 subjects (25 in the allopurinol group and 25 in the control group) participated in this study. Table 1 shows that the majority of the subjects in the current study were male. The most common etiology for CKD in the whole cohort was diabetes mellitus $(36.0 \%)$ followed by unknown cause (20.0\%) and GN (16.0\%) (Table 1). The mean age of the subjects was $54.04 \pm 12.62$ years. There was no significant difference in demographic characteristics between groups $(P>0.05)$ except for diastolic blood

Table 1. Comparison of demographic characteristics between study groups

\begin{tabular}{|c|c|c|c|c|c|}
\hline \multirow[t]{2}{*}{ Variable } & $\begin{array}{c}\text { Total } \\
(\mathrm{N}=50)\end{array}$ & $\begin{array}{c}\text { Allopurinol } \\
(n=25)\end{array}$ & $\begin{array}{l}\text { Control } \\
(n=25)\end{array}$ & \multirow[t]{2}{*}{$x^{2}$} & \multirow[t]{2}{*}{$P$} \\
\hline & No. (\%) & No. (\%) & No. (\%) & & \\
\hline \multicolumn{6}{|l|}{ Gender } \\
\hline Male & $36(72.0)$ & $17(68.0)$ & $19(76.0)$ & \multirow{2}{*}{0.40} & \multirow{2}{*}{0.53} \\
\hline Female & $14(28.0)$ & $8(32.0)$ & $6(24.0)$ & & \\
\hline Smoking & $11(22.0)$ & $5(20.0)$ & $6(24.0)$ & 0.12 & 0.73 \\
\hline \multicolumn{6}{|l|}{ Etiology } \\
\hline DM & $18(36.0)$ & $13(52.0)$ & $5(20.0)$ & \multirow{6}{*}{9.30} & \multirow{6}{*}{0.16} \\
\hline Unknown & $10(20.0)$ & $3(12.0)$ & $7(28.0)$ & & \\
\hline GN & $8(16.0)$ & $2(8.0)$ & $6(24.0)$ & & \\
\hline HTN & $7(14.0)$ & $3(12.0)$ & $4(16.0)$ & & \\
\hline Nephrolithiasis & $4(8.0)$ & $3(12.0)$ & $1(4.0)$ & & \\
\hline Reflux & $1(2.0)$ & $0(0.0)$ & $1(4.0)$ & & \\
\hline
\end{tabular}

DM; diabetes mellitus, GN; glomerulonephritis, HTN; hypertension. pressure $(P=0.002)$ (Tables 1 and 2$)$.

There were no significant differences in outcome between the two groups at baseline $(P>0.05)$ (Table 3$)$. The ANCOVA revealed a significant effect $(P<0.05)$ for all variables except uric acid $(P=0.96)$ and significant timexgroup effect for all outcome $(P<0.05)$ (Table 3 ). Intervention resulted in a significant reduction in serum uric acid $(P<0.001)$, and a significant increase in serum bicarbonate, $\mathrm{pH}(P<0.001$ for each variable) and GFR $(P=0.002)$ in the allopurinol administered group. No significant difference was observed in serum creatinine between baseline and three months of intervention in allopurinol administered group $(P=0.10)$. Among the subjects in control group a significant reduction was observed in serum uric acid $(P=0.01)$ and GFR $(P=0.003)$, and also a significant rise in serum creatinine at three months versus baseline $(P=0.01)$ (Table 3 ).

\section{Discussion}

This study showed that the mean age of CKD patients was $54.04 \pm 12.62$ years. This finding was in line with previous studies $(10,11)$. On the other hand, the majority of the subjects in the current study were male which was in contrast to the higher reported prevalence of CKD among females. This difference might be due to small sample size of the current study, while our sample size was defined based on RCT design $(10,12)$. Furthermore diabetes mellitus was the major underlying cause of CKD in the current study which was in line with the previous studies in the region $(13,14)$.

The findings of this study revealed that inclusion of allopurinol in the treatment of CKD patients resulted in a significant increase in serum bicarbonate and $\mathrm{PH}$. This effect was observed regardless of the increased GFR and reduced serum uric acid in both intervention and control group. This finding was similar to the findings of a previous study in which three months administration of allopurinol in $30 \mathrm{CKD}$ patients in the stages II to IV resulted in improved endothelial function and acidosis $(9,15,16)$. Although the mechanism of allopurinol action is yet unknown, animal studies have demonstrated that uric acid reduction might result in improvement of blood pressure and proteinuria and therefore reduce the progression of CKD by reducing the production of reactive oxygen species (17-20).

This study also showed a significant increase in GFR in

Table 2. Comparison of age and blood pressure between study groups

\begin{tabular}{lcccc}
\hline & Total & Allopurinol & Control & $\boldsymbol{t}$ \\
\hline Age $(\mathrm{y})$ & $54.04 \pm 12.62$ & $56.12 \pm 11.79$ & $51.96 \pm 13.31$ & 1.17 \\
Systolic blood pressure $(\mathrm{mm} \mathrm{Hg})$ & $135.60 \pm 15.99$ & $132.80 \pm 19.90$ & $138.40 \pm 10.48$ & -1.24 \\
Diastolic blood pressure $(\mathrm{mm} \mathrm{Hg})$ & $82.00 \pm 10.25$ & $77.60 \pm 11.56$ & $86.40 \pm 6.38$ & -3.33 \\
\hline
\end{tabular}

\footnotetext{
** Significant at $\alpha=0.01$.
} 
Table 3. Changes in study variables in allopurinol and control groups

\begin{tabular}{|c|c|c|c|c|c|c|c|c|c|c|c|}
\hline \multirow[b]{2}{*}{ Variable } & \multicolumn{3}{|c|}{ Allopurinol } & \multicolumn{3}{|c|}{ Control } & \multicolumn{2}{|c|}{$\begin{array}{c}\text { Allopurinol versus } \\
\text { control }\end{array}$} & \multirow{2}{*}{$\begin{array}{l}\text { Time } \\
\text { effect }\end{array}$} & \multirow{2}{*}{$\begin{array}{l}\text { Group } \\
\text { effect }\end{array}$} & \multirow{2}{*}{$\begin{array}{c}\text { Time*group } \\
\text { effect }\end{array}$} \\
\hline & Baseline & 3 months & $\begin{array}{l}\text { Baseline } \\
\text { vs } 3 \\
\text { months }\end{array}$ & Baseline & 3 months & $\begin{array}{l}\text { Baseline } \\
\text { vs } 3 \\
\text { months }\end{array}$ & Baseline & $\begin{array}{c}3 \\
\text { months }\end{array}$ & & & \\
\hline $\begin{array}{l}\text { Uric acid } \\
\text { (mg/dL) }\end{array}$ & $7.34 \pm 1.00$ & $5.74 \pm 0.97$ & $<0.001^{\mathrm{b}}$ & $6.59 \pm 0.54$ & $5.99 \pm 0.83$ & $0.01^{b}$ & 0.08 & 0.32 & 0.77 & 0.96 & $0.005^{b}$ \\
\hline $\begin{array}{l}\mathrm{HCO}_{3} \\
(\mathrm{mEq} / \mathrm{L})\end{array}$ & $19.64 \pm 0.44$ & $22.92 \pm 1.32$ & $<0.001^{\mathrm{b}}$ & $19.83 \pm 0.29$ & $19.75 \pm 1.82$ & 0.33 & 0.73 & $<0.001^{b}$ & 0.21 & $<0.001^{b}$ & $<0.001^{b}$ \\
\hline $\mathrm{pH}$ & $7.31 \pm 0.03$ & $7.37 \pm 0.32$ & $<0.001^{b}$ & $7.31 \pm 0.04$ & $7.30 \pm 0.43$ & 0.13 & 0.75 & $<0.001^{b}$ & 0.54 & $0.001^{\mathrm{b}}$ & $<0.001^{\mathrm{b}}$ \\
\hline $\begin{array}{l}\text { GFR } \\
(\mathrm{mL} / \mathrm{min} / 1.73 \\
\left.\mathrm{m}^{2}\right)\end{array}$ & $34.19 \pm 11.15$ & $37.15 \pm 14.33$ & $0.002^{b}$ & $36.75 \pm 8.45$ & $34.01 \pm 6.94$ & $0.003^{b}$ & 0.91 & 0.05 & 0.19 & $0.03^{a}$ & $<0.001^{b}$ \\
\hline $\begin{array}{l}\text { Creatinine } \\
(\mathrm{mg} / \mathrm{dL})\end{array}$ & $2.09 \pm 0.41$ & $2.03 \pm 0.61$ & 0.10 & $2.00 \pm 0.44$ & $2.12 \pm 0.45$ & $0.01^{\mathrm{b}}$ & 0.90 & 0.12 & 0.12 & $0.02^{\mathrm{a}}$ & $0.01^{\mathrm{b}}$ \\
\hline
\end{tabular}

$\mathrm{HCO}_{3}$, bicarbonate; GFR, glomerular filtration rate.

a Significant at $\alpha=0.05$.

${ }^{\mathrm{b}}$ Significant at $\alpha=0.01$.

the intervention group and a significant decline in GFR in the control group. However, at the end of three months there was only a trend in higher GFR in the allopurinol treated versus the controls $(P=0.05)$. Although the difference was non-significant, however allopurinol administration was found to increase GFR more than placebo. This finding was in line with the findings of a previous study that reported a significant improvement in GFR and creatinine due to the administration of allopurinol (8).

\section{Conclusion}

The findings of the current study revealed that allopurinol administration might result in reduced metabolic acidosis and GFR in CKD patients by reducing serum uric acid levels

\section{Study limitations}

This study did not assess the mechanism of action of allopurinol on reducing metabolic acidosis in CKD patients. Further studies are recommended.

Another, limitation of this study was the assessment of few serum biomarkers of kidney function and other metabolic clues that might lead to the understanding the mechanism of allopurinol action in CKD.

\section{Authors' contribution}

MM and MH designed the study, observed accuracy and validity of the study. DG collected the data and follow the study. MM supervised the project. MM and $\mathrm{BH}$ wrote the paper. All authors edited and revised the final manuscript and accepted its publication.

\section{Conflicts of interest}

The authors declared no competing interests.

\section{Ethical considerations}

Ethical issues (including plagiarism, data fabrication, double publication) have been completely observed by the authors.

\section{Funding/Support}

Vice chancellor for research Mashhad University of Medical Sciences supported this study (Grant \#950015).

\section{References}

1. Hill NR, Fatoba ST, Oke JL, Hirst JA, O'Callaghan CA, Lasserson DS, et al. Global prevalence of chronic kidney disease - a systematic review and meta-analysis. PLoS One. 2016; 11:e0158765. doi: 10.1371/journal.pone.0158765.

2. Webster AC, Nagler EV, Morton RL, Masson P. Chronic kidney disease. Lancet. 2017;389:1238-1252.

3. Kabul S, Shepler B. A review investigating the effect of allopurinol on the progression of kidney disease in hyperuricemic patients with chronic kidney disease. Clin Ther. 2012;34:2293-2296.

4. Sampson AL, Singer RF, Walters GD. Uric acid lowering therapies for preventing or delaying the progression of chronic kidney disease. Cochrane Database Syst Rev. 2017; 10:CD009460. doi: 10.1002/14651858.CD009460.

5. Yelken B, Caliskan Y, Gorgulu N, Altun I, Yilmaz A, Yazici $\mathrm{H}$, et al. Reduction of uric acid levels with allopurinol treatment improves endothelial function in patients with chronic kidney disease. Clin Nephrol. 2012;77:275-82.

6. Johnson RJ, Nakagawa T, Jalal D, Sánchez-Lozada LG, Kang D-H, Ritz E. Uric acid and chronic kidney disease: which is chasing which? Nephrol Dial Transplant. 2013;28:2221-8.

7. Goicoechea M, de Vinuesa SG, Verdalles U, Ruiz-Caro C, Ampuero J, Rincón A, et al. Effect of allopurinol in chronic kidney disease progression and cardiovascular risk. Clin J Am Soc Nephrol. 2010;5:1388-1393.

8. Siu Y-P, Leung K-T, Tong MK-H, Kwan T-H. Use of allopurinol in slowing the progression of renal disease 
through its ability to lower serum uric acid level. Am J Kidney Dis. 2006;47:51-59.

9. Bayram D, Sezer MT, İnal S, Altuntaş A, Kıdır V, Orhan H. The effects of allopurinol on metabolic acidosis and endothelial functions in chronic kidney disease patients. Clin Exp Nephrol. 2015;19:443-449.

10. Delanaye P, Glassock RJ, Pottel H, Rule AD. An agecalibrated definition of chronic kidney disease: rationale and benefits. Clin Biochem Rev. 2016;37:17-26.

11. Murphy D, McCulloch CE, Lin F, Banerjee T, BraggGresham JL, Eberhardt MS, et al. Trends in prevalence of chronic kidney disease in the United States. Ann Intern Med. 2016 Oct 4; 165:473-81.

12. Mills KT, Xu Y, Zhang W, Bundy JD, Chen C-S, Kelly TN, et al. A systematic analysis of world-wide population-based data on the global burden of chronic kidney disease in 2010. Kidney Int. 2015;88:950-7.

13. Asmat U, Abad K, Ismail K. Diabetes mellitus and oxidative stress-A concise review. Saudi Pharm J. 2016; 24:547-53.

14. Collins AJ, Foley RN, Gilbertson DT, Chen S-C. United States Renal Data System public health surveillance of chronic kidney disease and end-stage renal disease. Kidney Int Suppl. 2015;5:2-7. doi: 10.1038/kisup.2015.2.

15. Gao X, Lo EC-M, McGrath C, Ho SM-Y. Face-to-face individual counseling and online group motivational interviewing in improving oral health: study protocol for a randomized controlled trial. Trials. 2015;16:416.

16. Moviat M, Terpstra AM, Ruitenbeek W, Kluijtmans LA,
Pickkers P, van der Hoeven JG. Contribution of various metabolites to the "unmeasured" anions in critically ill patients with metabolic acidosis. Crit Care Med. 2008;36:752-758.

17. Kanji T, Gandhi M, Clase CM, Yang R. Urate lowering therapy to improve renal outcomes in patients with chronic kidney disease: systematic review and meta-analysis. BMC Nephrol. 2015;16:58. doi: 10.1186/s12882-015-0047-z.

18. Jalal DI, Chonchol M, Chen W, Targher G. Uric acid as a target of therapy in CKD. Am J Kidney Dis Off J Natl Kidney Found. 2013;61:134-46.

19. Kang D-H, Nakagawa T, Feng L, Watanabe S, Han L, Mazzali M, et al. A role for uric acid in the progression of renal disease. J Am Soc Nephrol JASN. 2002; 13:2888-97.

20. Sánchez-Lozada LG, Tapia E, Santamaría J, Avila-Casado C, Soto V, Nepomuceno T, et al. Mild hyperuricemia induces vasoconstriction and maintains glomerular hypertension in normal and remnant kidney rats. Kidney Int. 2005; 67:23747.

21. Kosugi T, Nakayama T, Heinig M, Zhang L, Yuzawa Y, Sanchez-Lozada LG, et al. Effect of lowering uric acid on renal disease in the type 2 diabetic $\mathrm{db} / \mathrm{db}$ mice. Am J Physiol-Ren Physiol. 2009;297:F481-8. doi: 10.1152/ ajprenal.00092.2009.

22. Filiopoulos V, Hadjiyannakos D, Vlassopoulos D. New insights into uric acid effects on the progression and prognosis of chronic kidney disease. Ren Fail. 2012;34:51020. doi: 10.3109/0886022X.2011.653753.

Copyright (C) 2019 The Author(s); Published by Nickan Research Institute. This is an open-access article distributed under the terms of the Creative Commons Attribution License (http://creativecommons.org/licenses/by/4.0), which permits unrestricted use, distribution, and reproduction in any medium, provided the original work is properly cited. 